\title{
Protective effect of indomethacin in renal ischemia-reperfusion injury in mice"
}

\author{
Sheng-hong ZHU ${ }^{\S 1,2}$, Li-jia ZHOU ${ }^{\S 1}$, Hong JIANG ${ }^{1}$, Rong-jun CHEN $^{1}$, Chuan LIN $^{1}$, \\ Shi FENG ${ }^{1}$, Juan JIN ${ }^{1}$, Jiang-hua CHEN ${ }^{1}$, Jian-yong WU $^{\dagger+1}$ \\ ( ${ }^{1}$ Kidney Disease Center, the First Affiliated Hospital, School of Medicine, Zhejiang University, Hangzhou 310003, China) \\ ( ${ }^{2}$ Kidney Disease Center, Shaoxing Second Hospital, Shaoxing 312000, China) \\ †E-mail: wujianyong@medmail.com.cn \\ Received July 24, 2013; Revision accepted Nov. 18, 2013; Crosschecked May 26, 2014
}

\begin{abstract}
Objective: To evaluate the renoprotection effects of non-steroidal anti-inflammatory drugs (NSAIDs) in renal ischemia-reperfusion injury (IRI) and the cyclooxygenase (COX)-1/2 blockade association by indomethacin (IMT) in the mice model. Methods: After the left renal pedicle of mice was clamped, IMT was administrated by intraperitoneal injection with four doses: 1, 3, 5, and $7 \mathrm{mg} / \mathrm{kg}$. Blood and kidney samples were collected $24 \mathrm{~h}$ after IRI. The renal functions were assayed by the cytokines and serum creatinine ( $\mathrm{SCr}$ ) using enzyme-linked immunosorbent assay (ELISA) kits. Kidney samples were analyzed by hematoxylin and eosin (H\&E) and immunohistochemistry stainings. Results: The mice administered with $5 \mathrm{mg} / \mathrm{kg}$ IMT had a marked reduction in $\mathrm{SCr}$ and significantly less tubular damage. The tumor necrosis factor $\alpha$ (TNF- $\alpha$ ) activity in renal homogenates and interleukin 6 (IL-6) activity in serum had a marked reduction at doses of 5 and $7 \mathrm{mg} / \mathrm{kg}$ IMT. The administration of 3 and $5 \mathrm{mg} / \mathrm{kg}$ IMT had a marked reduction in the ratio of thromboxane $B_{2}$ to 6-keto-prostaglandin $F_{1 \alpha}$. COX-1 and COX-2 stainings were weaker in $5 \mathrm{mg} / \mathrm{kg}$ IMT groups than that in the other groups. Conclusions: There was a dose response in the IMT function of renal IRI in mice, and IMT had a protective effect in a certain dose range. The effect of IMT on mice IRI was related to COX-1/2 blockades.
\end{abstract}

Key words: Non-steroidal anti-inflammatory drug (NSAID), Indomethacin (IMT), Ischemia-reperfusion injury (IRI), Dosage, Protective effect doi: $10.1631 /$ jzus.B1300196

Document code: A

CLC number: R58

\section{Introduction}

In kidney transplantation, ischemia-reperfusion injury (IRI) contributes to the allograft dysfunction (Peeters et al., 2004; Chapman et al., 2005; Perco et al., 2007). In native kidneys, IRI is a common cause of acute kidney injury (AKI) in patients who are undergoing cardiac surgery or with critical illness, and it

\footnotetext{
¿ Corresponding author

$\S$ The two authors contributed equally to this paper

* Project supported by the National Key Technology R\&D Program of China (No. 2011BAI10B07), the National Basic Research Program (973) of China (No. 2012CB517603), and the National High-Tech R\&D Program (863) of China (No. 2012AA02A512)

(C) Zhejiang University and Springer-Verlag Berlin Heidelberg 2014
}

is associated with high mortality and morbidity (Levy et al., 1996; Schiffl et al., 2002; Chertow et al., 2005; Bellomo et al., 2008; Kellum et al., 2008; Kinsey et al., 2008). For decades, non-steroidal antiinflammatory drugs (NSAIDs) have been used successfully in the treatment of numerous clinical diseases for their anti-inflammatory and analgesic effects. Despite the efficacy, long-term use of NSAIDs could cause renal damage, such as renal papillary necrosis (John and Herzenberg, 2009). Does the short-term and low-dose application of NSAIDs have the same damage, such as patient-controlled analgesia (PCA)?

PCA is usually used for relieving pain after major surgery. NSAIDs are commonly combinated 
with morphine following major surgery with the aim of reducing morphine's side-effects (McDaid et al., 2010). PCA has reduced the morbidity of cardiac, pulmonary, thromboembolic and renal diseases, and also reduced blood loss and transfusion requirements (Kehlet, 2004). However, many animal studies showed that NSAIDs have a protective effect on the IRI, such as heart, lung, and liver (Takeyoshi et al., 2001; Otani et al., 2007; Carnieto et al., 2009). Studies also showed that NSAIDs displayed a renal protective effect after IRI. The patients would take the treatment of NSAIDs for preoperative renal function normally, but NSAIDS can cause renal dysfunction in the early postoperative period. While the treatment was going on, the renal protective effect would occur (Lee et al., 2007).

Indomethacin (IMT) is one of the most widely used NSAIDs in clinics. An increasing number of studies reported that pretreatment with IMT alone tended to reduce the renal damage after IRI (Schneider et al., 2009). Feitoza et al. (2008) showed that pretreatment of mice with $5 \mathrm{mg} / \mathrm{kg}$ IMT could protect the renal function and reduce long-term renal fibrosis. The research on rats indicated that low-dose $(1 \mathrm{mg} / \mathrm{kg})$ of IMT adopted after ischemia prevented ischemiainduced down-regulation of Oat1/3 during reperfusion and had a significant protective effect on the renal function after AKI (Feitoza et al., 2002). In this study, we used the mice renal IRI model to evaluate the renoprotection effect of NSAIDs by IMT.

\section{Materials and methods}

\subsection{Animals}

Male mice (C57BL/6; 8-10 weeks, 20-24 g) were purchased from Shanghai SLAC Laboratory Animal Co., Ltd., China. All animals were housed individually in standard cages and had free access to a commercial pellet diet and tap water during the study. All procedures were previously reviewed and approved by the internal ethical committee.

\subsection{Murine model of renal IRI}

All procedures were performed using strict sterile techniques under general anesthesia with pentobarbital sodium $(50 \mathrm{mg} / \mathrm{kg}$, intraperitoneal (i.p.) injection). Animals were set on a warming table to maintain a rectal temperature of $37{ }^{\circ} \mathrm{C}$. A midline incision was made and a right nephrectomy performed. A microaneurysm clamp was used to occlude the left renal pedicle for $60 \mathrm{~min}$; the time of ischemia was chosen to obtain a reversible model of ischemic AKI without significant mortality. After the microaneurysm clamp was removed, reperfusion was confirmed visually by the blood flow returning to the kidney. The animals were administered $1 \mathrm{ml}$ of prewarmed $\left(37^{\circ} \mathrm{C}\right)$ sterile saline (i.p.), and the incisions were closed in two layers. The animals were then allowed to recover with free access to food and water. The sham-operated mice underwent dissection of the left renal pedicle without clamping after removal of the right kidney. After $24 \mathrm{~h}$, mice were re-anesthetized, the abdominal cavity was opened, and blood was obtained from inferior vena. The mice were killed and the kidney was harvested, one-half of each was fixed in $10 \%$ formalin, and the residual kidney was snap frozen in liquid nitrogen and stored at $-80{ }^{\circ} \mathrm{C}$ until further processing.

\subsection{Study design}

After the left renal pedicle was clamped, IMT (Sigma, USA) was administrated i.p. at four doses 1, 3,5 , and $7 \mathrm{mg} / \mathrm{kg}$. Animals were randomly divided into six groups $(n=6)$ :

Sham group: sham+saline;

IRI group (control): IRI+saline;

IRI+1IMT group: IRI+1 mg/kg IMT;

IRI+3IMT group: IRI+3 mg/kg IMT;

IRI+5IMT group: IRI+5 mg/kg IMT;

IRI+7IMT group: IRI+7 mg/kg IMT.

\subsection{Renal function}

Blood samples (about $0.8 \mathrm{ml}$ ) were obtained from each animal at $24 \mathrm{~h}$ post-reperfusion and centrifuged at $2000 \mathrm{~g}$ for $5 \mathrm{~min}$ to obtain the serum. Serum creatinine (SCr) levels were measured as a marker of renal function, using a creatinine kit (Biovision, USA), and analyzed on a microplate reader.

\subsection{Serum cytokines}

Serum levels of tumor necrosis factor $\alpha(\mathrm{TNF}-\alpha)$, interleukin (IL)-6 (Groundwork Biotechnology Diagnosticate, USA), thromboxane $\mathrm{B}_{2}\left(\mathrm{TxB}_{2}\right)$, and 6-ketoprostaglandin $\mathrm{F}_{1 \alpha}\left(\mathrm{PGF}_{1 \alpha}\right)$ (Cayman Chemical Company, USA) were measured using enzyme-linked immunosorbent assay (ELISA) kits according to the manufacturer's instructions. 


\subsection{Histological examination}

The renal tissues were fixed in $10 \%$ neutral buffered formalin for $24 \mathrm{~h}$, and embedded in paraffin, sectioned at $3 \mu \mathrm{m}$ according to the standard procedure. The sections were deparaffinized and hydrated gradually and then stained with hematoxylin and eosin (H\&E). Tissue sections were scored in a blinded manner to evaluate the degree of tubular necrosis as described by Wan et al. (2011). Tubulointerstitial injury was defined as tubular necrosis, tubular dilatation and/or atrophy, inflammatory cell infiltrate, or cellular edema, and was graded on a scale based on the percentage of tubular affected: 0, normal kidney; 1 , minimal necrosis $(<5 \%) ; 2$, mild necrosis $(5 \%$ $25 \%) ; 3$, moderate necrosis $(25 \%-75 \%) ; 4$, severe necrosis $(>75 \%)$.

\subsection{Immunohistochemical staining}

Tissues sections of 2- $\mu \mathrm{m}$ thick were dewaxed in xylene and hydrated in graded series of alcohols, and then sections were placed in citrate buffer $(\mathrm{pH} \mathrm{6.0)}$ at $120{ }^{\circ} \mathrm{C}$ for $10 \mathrm{~min}$. Endogenous peroxidase activity was blocked with $0.3 \% \mathrm{H}_{2} \mathrm{O}_{2}$ for $30 \mathrm{~min}$ at room temperature. Non-specific binding was inhibited by incubation for $15 \mathrm{~min}$ with normal goat serum. Then, the sections were incubated with primary antibody rabbit anti-mouse against cyclooxygenase (COX)-1 (500× diluted; BioVision) or rabbit anti-mouse against COX-2 (100× diluted; Epitomics) for $60 \mathrm{~min}$ at $37^{\circ} \mathrm{C}$. After washing with phosphate buffered saline (PBS), the sections were incubated for $30 \mathrm{~min}$ with horse radish peroxidase-conjugated secondary antibody (ChemMate ${ }^{\mathrm{TM}}$ EnVision ${ }^{\mathrm{TM}}$ Detection kit). The final detection was performed using freshly prepared $\mathrm{DAB}$ as a chromogen, and the colorimetric reaction was allowed to proceed for $1 \mathrm{~min}$. The sections were evaluated blindly by counting the labeled cells in triplicate within 40 high-power fields per section.

The intensity of staining was graded as + (weak), ++ (moderate), or +++ (strong), and the number of positive cells was scored as $<25 \%, 26 \%-50 \%$, or $>50 \%$ (Miranda et al., 2000).

\subsection{Statistical analyses}

All data are expressed as mean \pm standard error (SE). The Student's unpaired $t$-test was used to compare two groups. All analyses were carried out using the GraphPad Prism 5.0 statistical software package, and $P<0.05$ was accepted as statistically significant.

\section{Results}

\subsection{IMT ameliorates renal dysfunction}

We first induced renal IRI models in mice and treated them with IMT or saline as control. By comparison to the sham animals, control animals subjected to renal IRI had apparent increased $\mathrm{SCr}$ at $24 \mathrm{~h}$, indicating the acute renal dysfunction ( $P=0.000005$ ) (Fig. 1, Table 1). However, the mice administered with $5 \mathrm{mg} / \mathrm{kg}$ IMT after renal IRI had a marked reduction in SCr vs. the IRI group (control) $(P=0.034)$. The mice administered with $1,3,7 \mathrm{mg} / \mathrm{kg}$ of IMT had no significant differences in $\mathrm{SCr}$ compared with the IRI group.

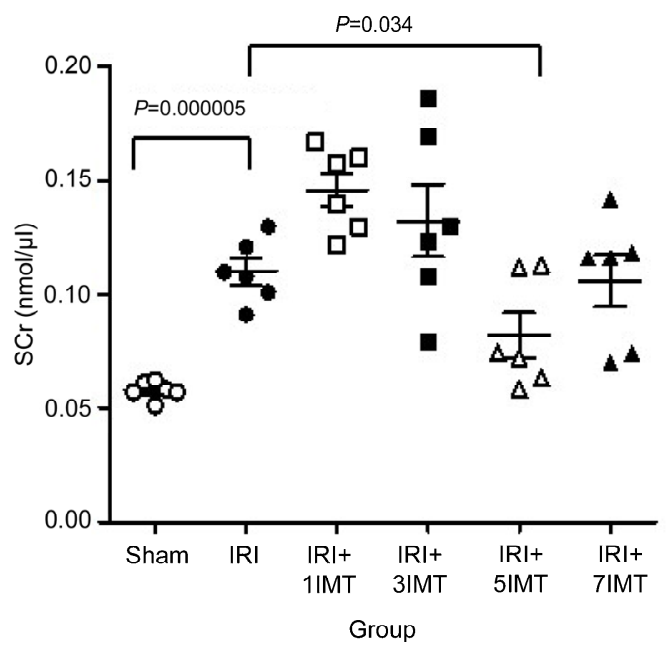

Fig. 1 Effect of IMT on renal dysfunction The sham group had a lower SCr than the IRI group $(P=0.000005)$. The $5 \mathrm{mg} / \mathrm{kg}$ IMT treatment group (IRI+5IMT) significantly decreased SCr compared to the IRI group $(P=0.034)$. The IRI+1IMT and IRI+3IMT group had higher Scr than the IRI group $(P=0.003$ and 0.220 , respectively). The IRI+7IMT group had no significant differences in Scr compared with the IRI group $(P=0.752)$

Table 1 Serum creatinine (SCr) after renal IRI

\begin{tabular}{ccc}
\hline Group & $\mathrm{SCr}^{*}(\mathrm{nmol} / \mu \mathrm{l})$ & $\begin{array}{c}P \text { value } \\
\text { (vs. control) }\end{array}$ \\
\hline Sham & $0.058 \pm 0.004$ & 0.000005 \\
IRI (control) & $0.110 \pm 0.013$ & \\
IRI+1IMT & $0.146 \pm 0.036$ & 0.003 \\
IRI+3IMT & $0.133 \pm 0.039$ & 0.220 \\
IRI+5IMT & $0.082 \pm 0.024$ & 0.034 \\
IRI+7IMT & $0.106 \pm 0.028$ & 0.752 \\
\hline
\end{tabular}

${ }^{*}$ Data are presented as mean \pm SE $(n=6)$ 


\subsection{IMT attenuates the histologic damage}

Histology analysis indicated the kidneys from the IRI group had severe tubular injury in the outer medulla, as evidenced by widespread tubular necrosis, luminal congestion, and significant infiltration of neutrophils at $24 \mathrm{~h}$ reperfusion. In contrast, renal sections from animals treated with $5 \mathrm{mg} / \mathrm{kg}$ IMT showed less tubular injury (Fig. 2e). However, renal sections obtained from animals treated with other doses of IMT $(1,3,7 \mathrm{mg} / \mathrm{kg})$ showed similar tubular injury as control (Figs. 2c, 2d, and 2f). Quantification of the tubular injury and infiltrating neutrophils in the outer medulla shows a significantly lower mean tubular injury score from the kidneys of mice treated with $5 \mathrm{mg} / \mathrm{kg}$ IMT (IRI $(2.333 \pm 0.516)$ vs. IRI+5IMT (1.667 \pm 0.516$), P=0.049)$, but no statistically different mean tubular injury score from the kidneys of mice treated with 1,3 , and $7 \mathrm{mg} / \mathrm{kg}$ IMT in comparison with the control group (Fig. $2 \mathrm{~g}$ ).

\subsection{IMT reduces TNF- $\alpha$ and IL-6 expression lev- els after renal IRI}

It was well known that monocytes/macrophages invading the renal cortical tissue are part of an inflammatory response after ischemia. Thus, the amounts of TNF- $\alpha$ and IL- 6 had been determined as markers of renal inflammatory response after ischemia and $24 \mathrm{~h}$ reperfusion. Compared with the IRI group, the IMT-treated mice showed significant down-regulation of TNF- $\alpha$ and IL-6 expression levels with the increase in the dose. The mice administered with 5 and $7 \mathrm{mg} / \mathrm{kg}$ IMT had a marked reduction in TNF- $\alpha$ activity in renal homogenates: IRI $(60.63 \pm$ $5.55) \mathrm{pg} / \mathrm{ml}$ vs. IRI+5IMT $(47.47 \pm 7.69) \mathrm{pg} / \mathrm{ml}$ $(P=0.007) \quad$ and IRI+7IMT $\quad(41.65 \pm 7.84) \quad \mathrm{pg} / \mathrm{ml}$ $(P=0.001)$ (Fig. 3a, Table 2$)$. A similar result was also detected in the IL-6 activity in serum: IRI (121.96 \pm 28.10) $\mathrm{pg} / \mathrm{ml}$ vs. IRI+5IMT $(75.00 \pm 36.21) \mathrm{pg} / \mathrm{ml}$ $(P=0.031)$ and IRI+7IMT $(60.74 \pm 35.76) \quad \mathrm{pg} / \mathrm{ml}$ $(P=0.008)$ (Fig. 3b, Table 2).

\subsection{IMT impact on $\mathrm{TxB}_{2}$ and 6-keto-PGF $\mathrm{Pa}_{1 \alpha} \mathrm{ex}-$ pression after renal IRI}

Prostanoids have long been known to behave as important physiological and pathological mediators implicated in a number of therapeutic areas of interest. In the kidney, vasodilator prostaglandins $\left(\mathrm{PGI}_{2}, \mathrm{PGE}_{2}\right.$, and $\mathrm{PGD}_{2}$ ) play an important role in regulating renal blood flow, diminishing vascular resistance, dilating renal vascular beds, and enhancing organ perfusion. On the contrary, thromboxane $\mathrm{A}_{2}\left(\mathrm{TxA}_{2}\right)$ is a

(a)

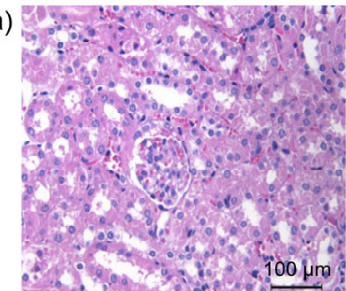

(c)
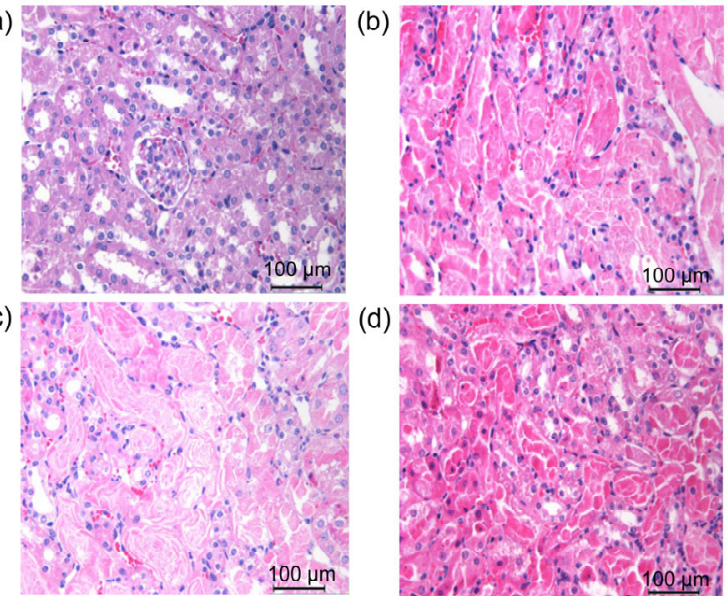

(e)

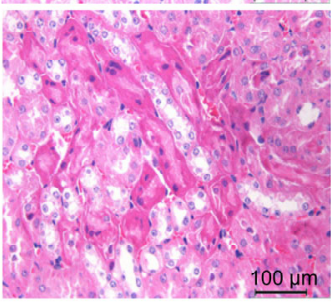

(d)

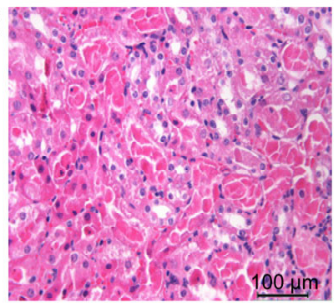

(f)

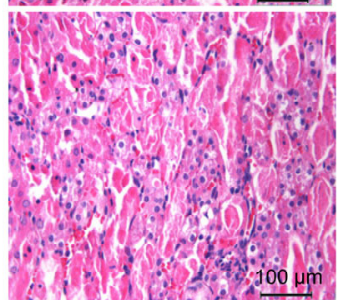

(g)

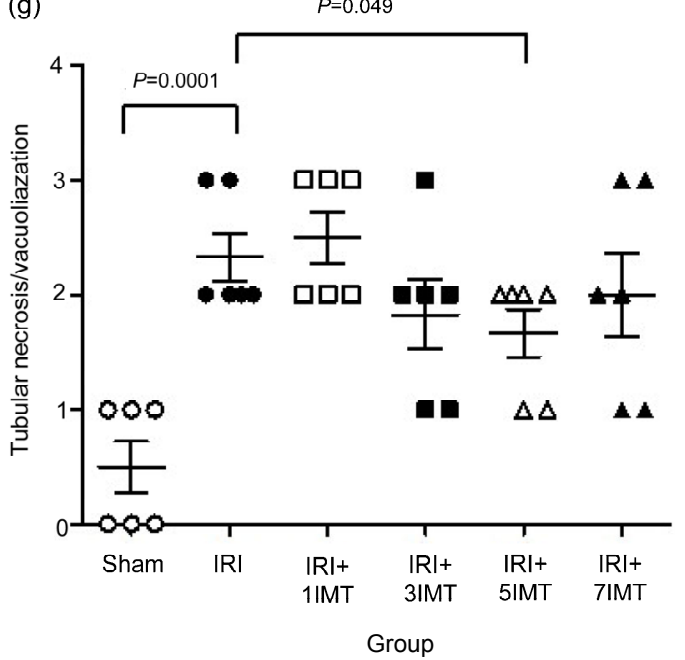

Fig. 2 Effects of IMT on histologic damage of mice renal H\&E histopathological section of kidney from sham (a); IRI (b); IRI+1IMT (c); IRI+3IMT (d); IRI+5IMT (e); IRI+7IMT (f). Scores for acute tubular necrosis from six groups $(\mathrm{g})$. The IRI group had a higher scores than the sham group $(P=0.0001)$, IRI+5IMT group had lower scores than the IRI group $(P=0.049)$, and 1,3 , and $7 \mathrm{mg} / \mathrm{kg}$ IMT groups had no significant difference compared with the IRI group $(P=0.599,0.209$, and 0.448 , respectively) 

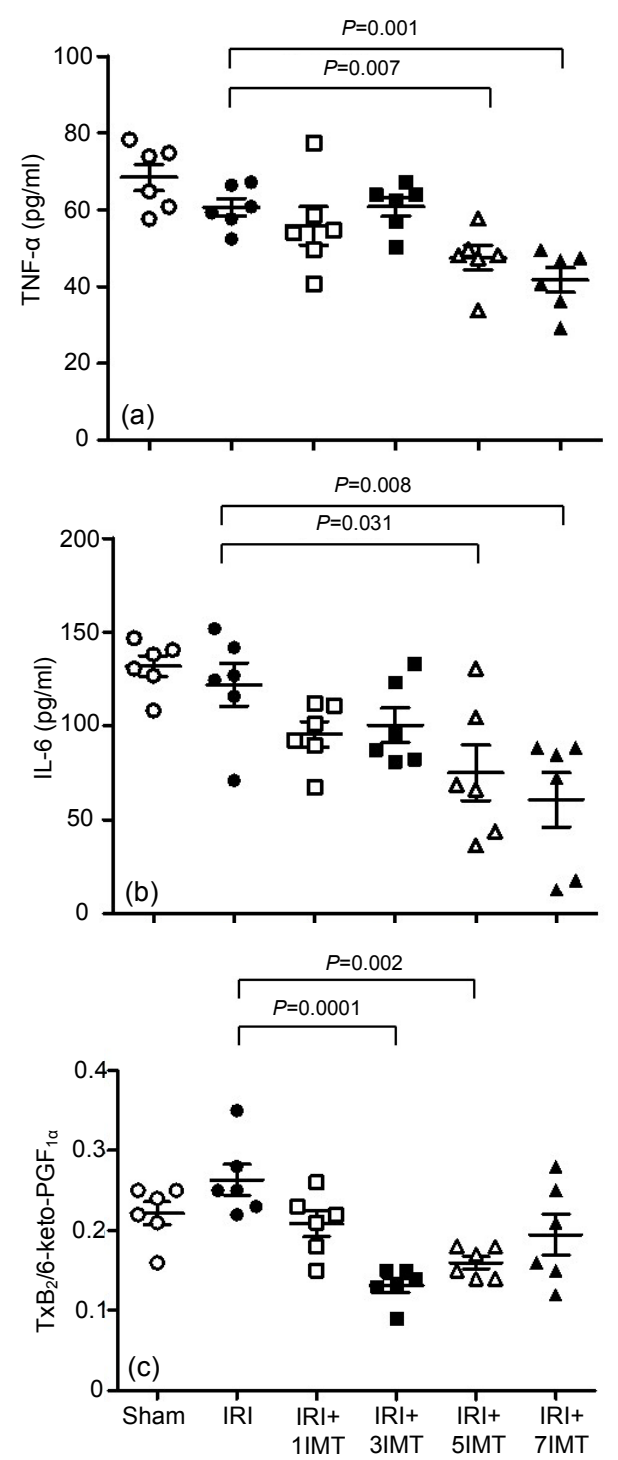

Fig. 3 Effects of IMT on expression levels of TNF- $\alpha$ (a), IL-6 (b), and TxB $/ 6$-keto-PGF $1 \alpha$ (c) after renal IRI IRI+5IMT and IRI+7IMT groups have significantly lower TNF- $\alpha$ (a) and IL-6 (b) levels than the IRI group; IRI+3IMT and IRI+5IMT groups have lower $\mathrm{TxB}_{2} / 6$-keto-PGF $1 \alpha$ than the IRI group (c) vasoconstriction. $\mathrm{TxB}_{2}$ is a metabolite of $\mathrm{TxA}_{2}$ and 6-keto- $\mathrm{PGF}_{1 \alpha}$ is a metabolite of $\mathrm{PGI}_{2}$. There is a $\mathrm{U}$-shaped dose-response curve on the ratio of $\mathrm{TxB}_{2}$ to 6-keto-PGF $\mathrm{Pa}_{1 \alpha}$. Here, the administration of 1 and $7 \mathrm{mg} / \mathrm{kg}$ IMT to mice does not significantly improve renal blood flow. The mice administered 3 and $5 \mathrm{mg} / \mathrm{kg}$ IMT have a marked reduction in $\mathrm{TxB}_{2} /$ 6-keto-PGF $1 \alpha$ : IRI $0.36 \pm 0.05$ vs. IRI +3 IMT $0.23 \pm$ $0.02(P=0.0001)$ and IRI+5IMT $0.26 \pm 0.02(P=0.002)$ (Fig. 3c, Table 2).

\subsection{Immunohistochemical analyses of COX-1 and COX-2}

The IRI group had strong COX-1 and COX-2 staining $(++-+++)$ in the renal tubes (number of positive cells $>50 \%$; Figs. $4 \mathrm{a}-4 \mathrm{~d}$ ). For the $5 \mathrm{mg} / \mathrm{kg}$ IMT treatment group, COX-1 and COX-2 stainings were low in the renal tubes (number of positive cells $<25 \%$ ), and obviously much lighter (Figs. 4e-4h).

\section{Discussion}

Previous work on mice indicated that severe dysfunction after renal IRI was ameliorated by treatment with $5 \mathrm{mg} / \mathrm{kg}$ IMT i.p. (Feitoza et al., 2002; 2005). The research on rats showed low-dose $(1 \mathrm{mg} / \mathrm{kg})$ IMT had a substantial protective effect on kidney function after AKI (Schneider et al., 2009). In recent studies, we set $1,3,5$, and $7 \mathrm{mg} / \mathrm{kg}$ IMT treatment in the mice IRI model, and found that $5 \mathrm{mg} / \mathrm{kg}$ IMT was the proper dose in this study. It was the direct anti-inflammatory effects of IMT on renal proximal tubular cells, which contributed to the observed protection. And the hemodynamic effect of IMT was also dependent on the appropriate dose, which was due to different sensitivity responses to IMT dosages in different rodent species.

Table 2 Effects of IMT on expression levels of TNF- $\alpha$, IL-6, and $\mathrm{TxB}_{2} / 6-k e t o-\mathrm{PGF}_{1 \alpha}$ after renal IRI

\begin{tabular}{clcc}
\hline Group & TNF- $\alpha(\mathrm{pg} / \mathrm{ml})$ & IL-6 $(\mathrm{pg} / \mathrm{ml})$ & TxB $_{2} / 6-\mathrm{keto}_{-} \mathrm{PGF}_{1 \alpha}$ \\
\hline Sham & $68.380 \pm 8.431$ & $131.848 \pm 13.542$ & $0.322 \pm 0.034$ \\
IRI (control) & $60.627 \pm 5.551$ & $121.958 \pm 28.097$ & $0.363 \pm 0.047$ \\
IRI+1IMT & $55.787 \pm 12.216$ & $95.465 \pm 16.560$ & $0.308 \pm 0.039$ \\
IRI+3IMT & $60.784 \pm 6.153$ & $100.427 \pm 22.310$ & $0.232 \pm 0.022^{*}$ \\
IRI+5IMT & $47.469 \pm 7.692^{*}$ & $74.998 \pm 36.210^{*}$ & $0.260 \pm 0.019^{*}$ \\
IRI+7IMT & $41.652 \pm 7.837^{*}$ & $60.737 \pm 35.755^{*}$ & $0.295 \pm 0.062$ \\
\hline
\end{tabular}

${ }^{*} P<0.05$ vs. IRI group. Data are presented as mean \pm SE $(n=6)$ 


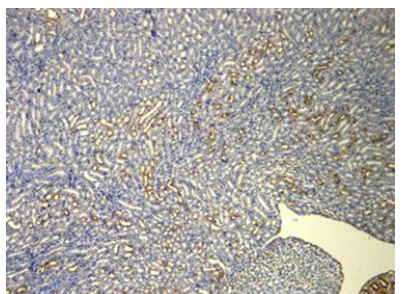

(a)

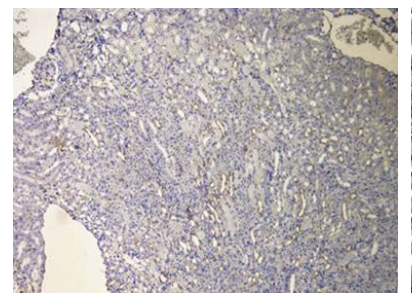

(e)

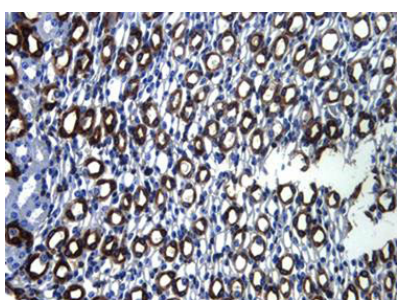

(b)

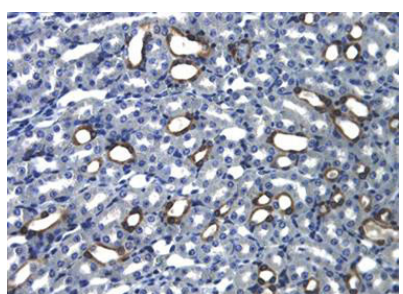

(f)

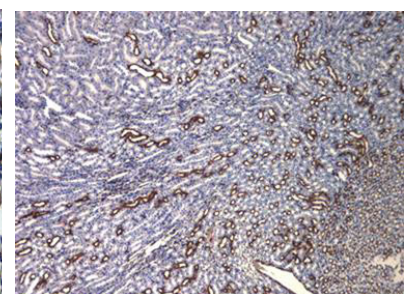

(c)

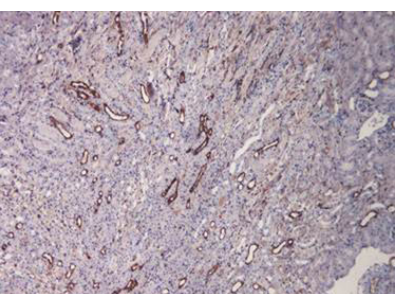

(g)

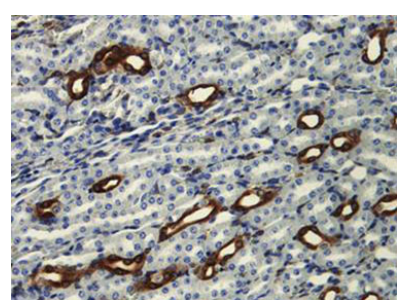

(d)

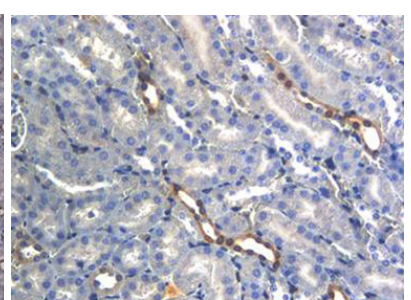

(h)

Fig. 4 Immunohistochemical analyses of COX-1 and COX-2

(a, b) IRI group had the COX-1 staining (++-+++) in the renal tubes, and the number of positive cells $>50 \%$; (c, d) IRI group had the COX-2 staining (++-+++) in the renal tubes, and the number of positive cells $>50 \%$; (e, f) $5 \mathrm{mg} / \mathrm{kg}$ IMT treatment group had the COX-1 staining $(+)$ in the renal tubes, and the number of positive cells $<25 \%$; $(\mathrm{g}, \mathrm{h}) 5 \mathrm{mg} / \mathrm{kg}$ IMT treatment group had the COX-2 staining $(+)$ in the renal tubes, and the number of positive cells $<25 \%$. (a, c, e, g) Magnification 10×; (b, d, f, h) Magnification 40×

Tissue injury after ischemia was not only caused by hypoxia from interrupted blood supply but also the activated inflammatory response by reperfusion. The peripheral leukocytes recruit and the interstitial cells proliferated in the target tissue (Ysebaert et al., 2004). An innate immune system was found to be important for the pathogenesis of IRI in recent years. This is mediated by numbers of cytokines/chemokines, adhesion molecules, transcription factors, and other pro-inflammatory factors which were specifically blocked for profound reduction of IRI (Kinsey et al., 2008; Lutz et al., 2010). Renal IRI induces inflammatory reactions within the renal parenchyma through increased synthesis of pro-inflammatory cytokines such as IL-1, IL-6, and TNF- $\alpha$ (Feitoza et al., 2002). TNF- $\alpha$ is a pro-inflammatory cytokine that upregulates its own expression and other cytokines that are pivotal to the inflammatory response (Donnahoo et al., 1999).

In human and experimental animals, glomerular filtration rate (GFR) reductions had been attributed to persistent vasoconstrictions, potentially contributed to by activation of tubuloglomerular feedback, which was also a result of enhanced delivery of the macula densa solution. Ischemic acute renal failure (ARF) had been referred to as "vasomotor nephropathy" in the past. Post-ischemic kidneys showed increased basal tone and reactivity to vasoconstriction agents, and decreased dilatory responses in arterioles (Bonventre and Weinberg, 2003). The $\mathrm{PGE}_{2}$ and $\mathrm{PGI}_{2}$ caused afferent arteriole dilatation and increased GFR, whereas thromboxanes led to constriction (Kinsey et al., 2008; Lutz et al., 2010). Maintenance of adequate renal function was dependent on homeostasis of substances, which causes mesangial relaxation and contraction. And this balance is shifted towards vasoconstriction, which was reflected by increased renal vascular resistance and decreased renal blood flow (Furtado et al., 2008).

Previous researches found that COX-1 and COX-2 participate in acute ischemic injury by evoking endothelial cells oxidative stress (Hamada et al., 2008; Feitoza et al., 2010; Talab et al., 2010). In our study, we found that the acute ischemic injury group had the higher COX-1 and COX-2 expression levels in the kidney. In $5 \mathrm{mg} / \mathrm{kg}$ IMT group, the kidney injury was light and the COX-1 and COX-2 expression levels were both lower than those in the IRI group. COX-1 and COX-2 are important for the AKI signaling pathway.

In conclusion, our study highlighted the important role of prophylactic IMT in the response to renal injury 
in mice. We showed that it involved the modulation of the immune response and renal haemodynamics, and the COX-1 and COX-2 expressions in AKI. Animal studies confirmed the renoprotective effect of IMT at an appropriate dose of $5 \mathrm{mg} / \mathrm{kg}$ in mice. There have been no human clinical trials for IMT in human renal IRI based on the consideration of drug safety. Does IMT have a similar effect in humans? And what dose is the most appropriate for humans? To solve these problems, we need further clinical trails for validation. Therefore, we are calling for more clinical trials to test whether IMT can exert a renoprotective effect during human renal IRI.

\section{Compliance with ethics guidelines}

Sheng-hong ZHU, Li-jia ZHOU, Hong JIANG, Rong-jun CHEN, Chuan LIN, Shi FENG, Juan JIN, Jiang-hua CHEN, and Jian-yong WU declare that they have no conflict of interest.

All institutional and national guidelines for the care and use of laboratory animals were followed.

\section{References}

Bellomo, R., Auriemma, S., Fabbri, A., et al., 2008. The pathophysiology of cardiac surgery-associated acute kidney injury (CSA-AKI). Int. J. Artif. Organs, 31(2): 166-178.

Bonventre, J.V., Weinberg, J.M., 2003. Recent advances in the pathophysiology of ischemic acute renal failure. $J . A m$. Soc. Nephrol., 14(8):2199-2210. [doi:10.1097/01.ASN. 0000079785.13922.F6]

Carnieto, A.Jr., Dourado, P.M., Luz, P.L., et al., 2009. Selective cyclooxygenase- 2 inhibition protects against myocardial damage in experimental acute ischemia. Clinics, 64(3):245-252. [doi:10.1590/S1807-59322009000300016]

Chapman, J.R., O'Connell, P.J., Nankivell, B.J., 2005. Chronic renal allograft dysfunction. J. Am. Soc. Nephrol., 16(10): 3015-3126. [doi:10.1681/ASN.2005050463]

Chertow, G.M., Burdick, E., Honour, M., et al., 2005. Acute kidney injury, mortality, length of stay, and costs in hospitalized patients. J. Am. Soc. Nephrol., 16(11): 3365-3370. [doi:10.1681/ASN.2004090740]

Donnahoo, K.K., Meng, X., Ayala, A., et al., 1999. Early kidney TNF- $\alpha$ expression mediates neutrophil infiltration and injury after renal ischemia-reperfusion. Am. J. Physiol. Regul. Integr. Comp. Physiol., 277(3):R922R929.

Feitoza, C.Q., Sanders, H., Cenedeze, M., et al., 2002. Pretreatment with indomethacin protects from acute renal failure following ischemia-reperfusion injury. Transpl. Proc., 34(7):2979-2980. [doi:10.1016/S0041-1345(02) 03507-8]

Feitoza, C.Q., Câmara, N.O., Pinheiro, H.S., et al., 2005.
Cyclooxygenase 1 and/or 2 blockade ameliorates the renal tissue damage triggered by ischemia and reperfusion injury. Int. Immunopharmacol., 5(1):79-84. [doi:10.1016/ j.intimp.2004.09.024]

Feitoza, C.Q., Goncalvs, G.M., Semedo, P., et al., 2008. Inhibition of COX1 and 2 prior to renal ischemia/reperfusion injury decreases the development of fibrosis. Mol. Med., 14(11-12):724-730. [doi:10.2119/2008-00064.Feitoza]

Feitoza, C.Q., Semedo, P., Gonçalves, G.M., et al., 2010. Modulation of inflammatory response by selective inhibition of cyclooxygenase- 1 and cyclooxygenase- 2 in acute kidney injury. Inflamm. Res., 59(3):167-175. [doi:10.1007/s00011-009-0083-x]

Furtado, N., Beier, U.H., Gorla, S.R., et al., 2008. The effect of indomethacin on systemic and renal hemodynamics in neonatal piglets during experimental endotoxemia. Pediatr. Surg. Int., 24(8):907-911. [doi:10.1007/s00383008-2175-z]

Hamada, T., Tsuchihashi, S., Avanesyan, A., et al., 2008. Cyclooxygenase- 2 deficiency enhances Th2 immune responses and impairs neutrophil recruitment in hepatic ischemia/reperfusion injury. J. Immunol., 180(3):18431853. [doi:10.4049/jimmunol.180.3.1843]

John, R., Herzenberg, A.M., 2009. Renal toxicity of therapeutic drugs. J. Clin. Pathol., 62(6):505-515. [doi:10.1136/ jcp.2008.058271]

Kehlet, H., 2004. Effect of postoperative pain treatment on outcome-current status and future strategies. Langenbecks Arch. Surg., 389(4):244-249. [doi:10.1007/s00423-0040460-4]

Kellum, J.A., Bellomo, R., Ronco, C., 2008. Definition and classification of acute kidney injury. Nephron Clin. Pract., 109(4):c182-c187. [doi:10.1159/000142926]

Kinsey, G.R., Li, L., Okusa, M.D., 2008. Inflammation in acute kidney injury. Nephron Exp. Nephrol., 109(4): e102-e107. [doi:10.1159/000142934]

Lee, A., Cooper, M.C., Craig, J.C., et al., 2007. Effects of nonsteroidal anti-inflammatory drugs on postoperative renal function in adults with normal renal function. Cochrane Database Syst. Rev., (2):CD002765. [doi:10. 1002/14651858.CD002765.pub3]

Levy, E.M., Viscoli, C.M., Horwitz, R.I., 1996. The effect of acute renal failure on mortality. A cohort analysis. JAMA, 275(19):1489-1494. [doi:10.1001/jama.1996.03530430 033035]

Lutz, J., Thürmel, K., Heemann, U., 2010. Anti-inflammatory treatment strategies for ischemia/reperfusion injury in transplantation. J. Inflamm., 7:27. [doi:10.1186/14769255-7-27]

McDaid, C., Maund, E., Rice, S., et al., 2010. Paracetamol and selective and non-selective non-steroidal anti-inflammatory drugs (NSAIDs) for the reduction of morphine-related side effects after major surgery: a systematic review. Health Technol. Assess., 14(17):1-153. [doi:10.3310/ hta14170]

Miranda, R.N., Briggs, R.C., Kinney, M.C., et al., 2000. 
Immunohistochemical detection of cyclin D1 using optimized conditions is highly specific for mantle cell lymphoma and hairy cell leukemia. Modern Pathol., 13(12):1308-1314. [doi:10.1038/modpathol.3880239]

Otani, Y., Takeyoshi, I., Yoshinari, D., et al., 2007. Effects of the COX-2 inhibitor FK3311 on ischemia-reperfusion injury in the rat lung. J. Invest. Surg., 20(3):175-180. [doi:10.1080/08941930701365986]

Peeters, P., Terryn, W., Vanholder, R., et al., 2004. Delayed graft function in renal transplantation. Curr. Opin. Crit. Care, 10(6):489-498. [doi:10.1097/01.ccx.0000146119. 46547.05]

Perco, P., Pleban, C., Kainz, A., et al., 2007. Gene expression and biomarkers in renal transplant ischemia reperfusion injury. Transpl. Int., 20(1):2-11. [doi:10.1111/j.14322277.2006.00376.x]

Schiffl, H., Lang, S.M., Fischer, R., 2002. Daily hemodialysis and the outcome of acute renal failure. N. Engl. J. Med., 346(5):305-310. [doi:10.1056/NEJMoa010877]

Schneider, R., Meusel, M., Renker, S., et al., 2009. Low-dose indomethacin after ischemic acute kidney injury prevents downregulation of Oat1/3 and improves renal outcome. Am. J. Physiol. Renal Physiol., 297(6):F1614-F1621. [doi:10.1152/ajprenal.00268.2009]

Takeyoshi, I., Sunose, Y., Iwazaki, S., et al., 2001. The effect of a selective cyclooxygenase-2 inhibitor in extended liver resection with ischemia in dogs. J. Surg. Res., 100(1): 25-31. [doi:10.1006/jsre.2001.6211]

Talab, S.S., Emami, H., Elmi, A., et al., 2010. Chronic lithium treatment protects the rat kidney againest ischemia/ reperfusion injury: the role of nitric oxide and cyclooxygenase pathways. Eur. J. Pharmacol., 647(1-3):171-177. [doi:10.1016/j.ejphar.2010.08.036]

Wan, X., Fan, L., Hu, B., et al., 2011. Small interfering RNA targeting IKK $\beta$ prevents renal ischemia-reperfusion injury in rats. Am. J. Physiol. Renal Physiol., 300(4): F857-F863. [doi:10.1152/ajprenal.00547.2010]

Ysebaert, D.K., de Greef, K.E., de Beuf, A., et al., 2004. $\mathrm{T}$ cells as mediators in renal ischemia/reperfusion injury. Kidney Int., 66(2):491-496. [doi:10.1111/j.1523-1755. 2004.761_4.x]

\section{中文概要:}

本文题目: 吲哚美辛对小鼠肾缺血再灌注损伤的保护作用

Protective effect of indomethacin in renal ischemia-reperfusion injury in mice

研究目的: 在小鼠模型中利用吲哚美辛阻断 COX-1/2 通路, 探讨非甾体类抗炎药对肾缺血再灌注损伤的 保护作用。

创新要点: 非甾体类抗炎药被认为具有肾毒性, 本研究首次在小鼠模型中探讨非甾体类抗炎药对肾缺血 再灌注损伤的保护作用。

研究方法: 小鼠左侧肾蒂夹闭后, 通过腹腔注射不同剂量的吗哚美辛, 在肾缺血再灌注损伤 24 小时后, 获取血液和肾脏标本。利用酶联免疫 (ELISA) 试剂盒测定血清肌酐和细胞因子浓度来评估 肾功能, 肾组织样本进行苏木精-伊红染色和免疫组化分析。

重要结论: 腹腔注射吲哚美辛 $5 \mathrm{mg} / \mathrm{kg}$ 组的小鼠血清肌酐值与对照组相比显著降低, 肾小管损伤也显著 减轻 (见图 1 和 2) ; 腹腔注射 5 和 $7 \mathrm{mg} / \mathrm{kg}$ 吲哚美辛组的小鼠血清肾肿瘤坏死因子 $-\alpha$ 和白 介素-6 的浓度显著降低 (见图 3a 和 $3 b$ ) ; 腹腔注射 3 和 $5 \mathrm{mg} / \mathrm{kg}$ 吲哚美辛组的小鼠血清血 栓素 $\mathrm{B}_{2}$ 与 6-酮前列腺素 $\mathrm{F}_{1 \alpha}$ 的比值明显降低 (见图 3c) ; 腹腔注射 $5 \mathrm{mg} / \mathrm{kg}$ 吲哚美辛组小鼠 肾组织 COX-1 和 COX-2 染色较弱（见图 4)。因此, 吲哚美辛对小鼠肾缺血再灌注损伤的 作用与其剂量相关, 在某个特定的剂量范围内具有肾保护作用。吲哚美辛对小鼠肾缺血再灌 注损伤的保护作用与阻断 COX-1/2 有关。

关键词组: 非甾体类抗炎药; 吲哚美辛; 缺血再灌注损伤; 剂量; 保护作用 